\title{
Modification of Chitosan-chitosan Phthalate Anhydrides Matrices
}

\author{
Lukman Atmaja, Herianus Manimoy, and Lina Eka Arizka
}

\begin{abstract}
Chitin and chitosan are natural biopolymers on shrimp shells. Chitosan is used extensively as a raw material in various industries. The study aimed to extract chitin and chitosan from fanami shrimp skin through deproteinization, demineralization, and deastilation reactions and to modify the matrix to improve the physical properties. The results of the analysis of the FTIR chitin spectrum shows several major peaks at wave number $3446.91 \mathrm{~cm}^{-1}$ which showed the vibrations of bending secondary amide and amine (NH) secondary amides at $1654.98 \mathrm{~cm}^{-1}$ indicating the presence of vibration stretching CH. The results of the chitosan FTIR spectrum analysis shows symmetrical stretching vibrations at $3433.41 \mathrm{~cm}^{-1} \mathrm{due}^{\mathrm{to}}$ overlapping $\mathrm{OH}$ and amines (NH), stretching vibrations of $1653.05 \mathrm{~cm}^{-1}$ caused by the propagation of $\mathrm{C}=\mathrm{O}$ stretching and stretching vibrations of $1587.47 \mathrm{~cm}^{-1}$ indicating secondary amide. The results of the characterization with XRD shows that extracted compounds were chitin and chitosan. In modifying the chitosan matrix, the spectra result show peak at 1656.91 . $1564.32 \mathrm{~cm}^{-1}$ indicating the presence of an amide group. New aromatic group peak found in the area of $1631.83 \mathrm{~cm}^{-1}$ which not found in chitosan. Diffract gram XRD from pure chitosan shows three highest peak peaks at $2 \theta$ equal to $609.2 ; 609.88$ and 550 while chitosan-anhydrous modification shows a peak at $2 \theta$ equal to 609.8 . The addition of anhydrous phthalates to chitosan has reduced its crystallinity which results in an increase in the hydrophilic characteristics of the membrane. The results of this study are expected to be one of the references in further research regarding the manufacture of phthalate chitosan-anhydrous based composite membranes for DMFC applications.
\end{abstract}

Keywords — Chitin, Chitosan, Phthalic Anhydride.

\section{INTRODUCTION}

$\mathrm{T}$ he availability of energy for human survival is one of the things faced by almost all countries in the world. Until now, world energy sources are still dominated by fossil fuels. The impact of the process of using energy from fossil fuels can influence the carrying capacity of the environment. $70 \%$ of the causes of air pollution are the result of motor vehicle emissions [1]. These conditions cause climate change and global warming that are destructive. In this regard, alternative energy that is sustainable, economical and low emissions is very necessary. One alternative energy source that has been continuously developed is fuel cells [2]. A fuel cell is an electrochemical cell that is able to convert chemical energy into electrical energy through an electrochemical reaction from the raw material of hydrogen with oxygen or other oxidizing substances. One of the most popular fuel cells developed is Direct Methanol Fuel Cell (DMFC). Direct Methanol Fuel Cell (DMFC) is one of several types of fuel cells that use Proton Exchange Membrane (PEM) as a link between reactions in the cathode and anode. This membrane uses methanol as a source of energy or fuel. This fuel cell directly utilizes methanol to produce energy. In addition, the most important component in DMFC is the electrolyte membrane, where the electrolyte membrane from DMFC acts as a means of transporting hydrogen ions $\left(\mathrm{H}^{+}\right)$ produced in the methanol oxidation reaction at the anode [3].

The commercial PEMs available are Nafion [4]. This type of membrane is made of synthetic polymer material, namely sulfonated tetrafluoroethylene (Wafiroh, 2016). Nafion has a high proton activity which is $4.7 \times 10-2 \mathrm{~S} /$ $\mathrm{cm}$ at temperatures $<100^{\circ} \mathrm{C}$, high thermal stability $(280$ ${ }^{\circ} \mathrm{C}$ ), and a low percentage of water absorption of $15.2 \%$. However, there is a weakness in the high permeability of

Lukman Atmaja, Herianus Manimoy, and Lina Eka Arizka is with Department of Chemistry, Institut Teknologi Sepuluh Nopember, Surabaya, 60111, Indonesia. E-mail: lukman_at@chem.its.ac.id.

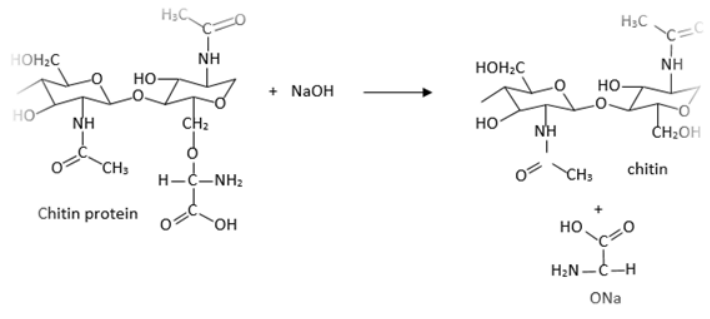

Figure 1. Deproteinization reaction.

methanol, which is equal to $27.6 \times 10^{-8} \mathrm{~cm}^{2} / \mathrm{s}$ [5]. Although Nafion is the most widely used membrane in PEM, the high permeability of methanol still disrupts its efficiency as a fuel cell. In addition, expensive Nafion prices have moved many scientists to conduct research to find other materials that can replace the role of Nafion [5].

Based on the electrolyte material, fuel cells are divided into several types, namely: Alkaline Fuel Cell (AFC), Phosphoric Acid Fuel Cell (PAFC), Molten Carbonate Fuel Cell (MCFC), Solid Oxide Fuel Cell (SOFC), Proton Exchange Membrane Fuel Cell (PEMFC), Direct Methanol Fuel Cell (DMFC), Regenerative Fuel Cells (RFCs), Zinc-Air Fuel Cells (ZAFC) [6]. Direct methanol fuel cell (DMFC) is one type of fuel cell that uses a proton exchange membrane (proton exchange membrane (PEM) as a link between reactions in the cathode and anode, has advantages compared to other types of fuel cells, including waste produced from this fuel is water and $\mathrm{CO}^{2}$ gas in small quantities, energy efficiency is quite high (exceeding 60\%), the heat produced due to the reaction process is very small, has good electrochemical activity, relatively low prices, easy handling (easy to handle, removed and stored) Therefore, DMFC is considered as a sustainable environmentally friendly energy source [6]. The composite membrane is a combination of inorganic material that enters the main polymer matrix. In other words, membrane composites are [7]:

a. Polymers with inorganic materials (at least one type of each polymer and organic material. 


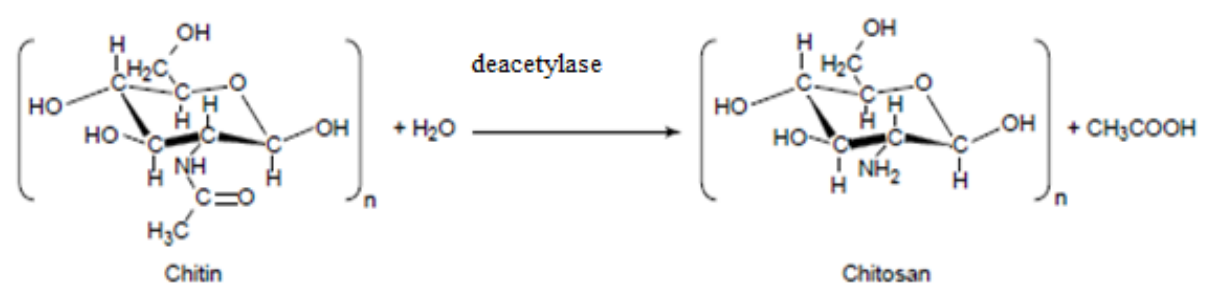

Figure 2. Deacetylation reaction in the process of making chitosan.

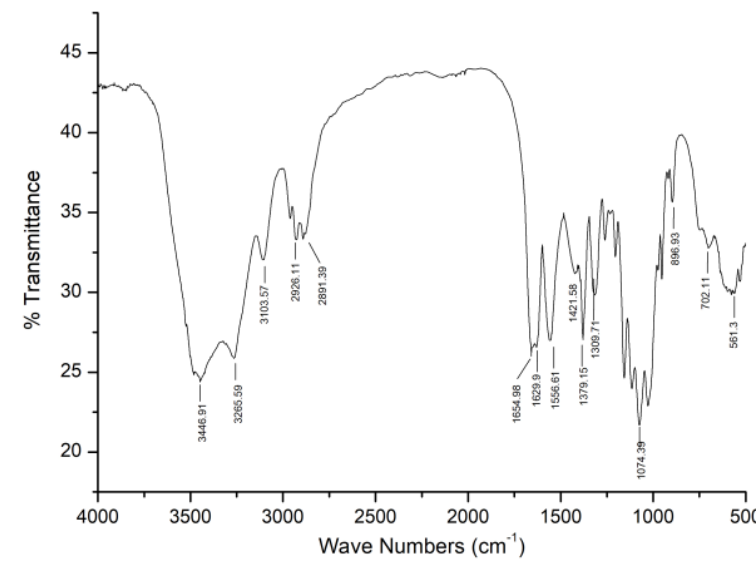

Figure 3. IR spectra chitin from fanami shrimp shells.

b. Some polymers (at least two types of organic components that have complementary properties).

Membrane composites are made by modifying from each component that has different properties in order to improve overall material performance [8]. Addition of inorganic material or other polymers into the main membrane polymer can improve the properties of the expected polymer composites in the electronic membrane, proton conductivity, methanol permeability, temperature stability, and mechanical strength. All these properties are very important to be able to be operated at DMFC.

This aim of this research is this research to reduce the crossover methanol while of maintaining the conductivity of the DMFC membrane, in the previous study. To obtain the physical properties of the electrolyte membrane, the matrix modified beam by adding anhydrous phthalate to chitosan. With the addition of Anhydrous Phthalate to chitosan, the membrane will improve the mechanical properties in order to increase conductivity and decrease the methanol crossover on the membrane when filled with fillers [9].

Many studies have been conducted to find natural electrolyte membranes that have the ability equivalent to PMM and PVDF at low production costs. One of the natural polymer compounds that can be used as a protoncarrying matrix solid electrolyte polymer membrane is chitosan [10].

Chitosan is a natural biopolymer material produced from chitin biopolymer, which is the second natural abundant biopolymer found in nature after cellulose. Chitin has been found in many sources such as marine crustaceans, insects, some algae, and fungi [11]. Chitosan is non- toxic, biodegradable and antimicrobial material which has many beneficial applications in many fields such as food industry, water treatment, manufacturing of membranes, cosmetics, antifungal and antibacterial products [12]. Chitosan is a bioproduct extracted from chitin by using alkali treatment which involves three main

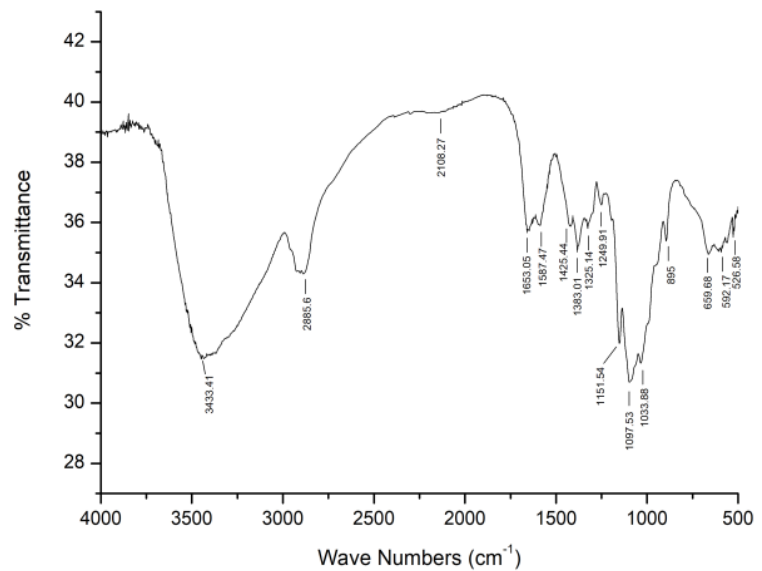

Figure 4. IR spectra chitosan from fanami shrimp shells.

steps. The first step is deproteinization (DP) step, which removes proteins and undesired materials such as pigments from shrimp shells. This is followed by demineralization (DM), which removes all minerals (e.g. $\mathrm{CaCO} 3$ ) by using acidic solution, then the deacetylation step (DD) which removes acetyl groups from the polymeric chain. The produced chitosan's quality depends on the conditions of extraction such as alkali concentrations and reaction time of acid with samples [13].

Chitosan has an active side in the form of an amine group (-NH2) and hydroxyl (-OH) which gives characteristics as ion exchangers [10][14]. However, in normal circumstances, chitosan has a low electrical conductivity because chitosan cannot be immobilized under the influence of an electric field to produce proton conductors [15]. In addition, the energy density of chitosan membranes is still relatively low and the hydrophilicity is still high so that the conductivity value is still relatively low to be applied in DMFC. This might be due to the difficulty of dissolving in general organic solvents. This is because the rigid crystal structure is caused by the formation of hydrogen bonds between amino groups and hydroxyl in chitosan monomers. To overcome this problem chitosan modification is necessary. The presence of amine groups (NH2) and hydroxyl $(\mathrm{OH})$ from chitosan causes chitosan to be easily chemically modified. The hydroxyl and amine groups can provide hydrogen bridges intermolecularly or intramolecularly. Thus a strong hydrogen network is formed, making chitosan insoluble in water. Various studies have been carried out to obtain the quality and utilization of chitosan in various applications. To tie chitosan quality, chitosan modification was carried out by inducing various functional groups into chitosan structures. Modification of chitosan with phthalic anhydride will increase load density, can produce phthalate chitosan compounds that are not easily 

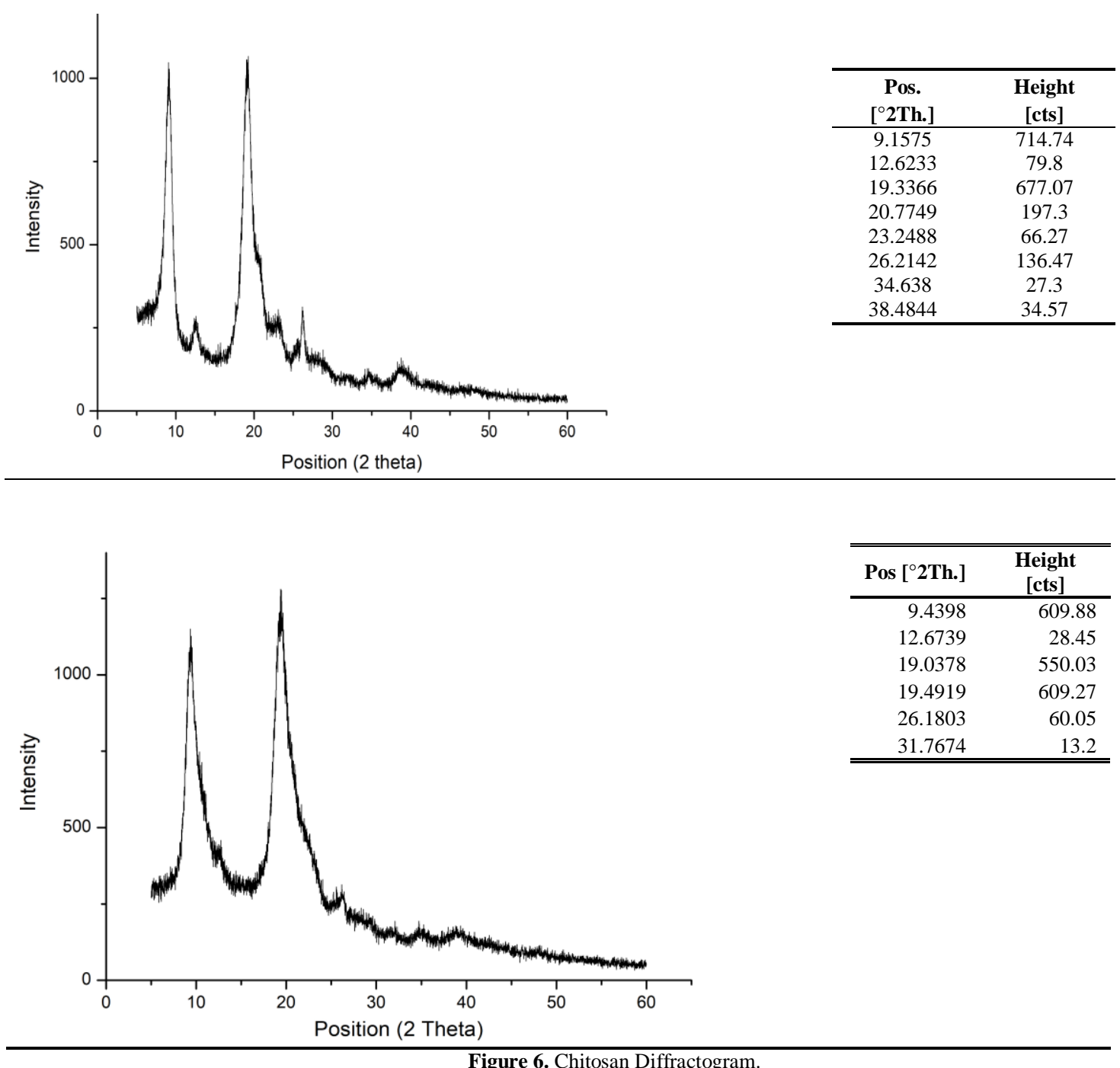

dissolved by high-level substitution, with the end-chain chain $\mathrm{COCOOH}$ which is easily ionized so that it has the potential to become ion transmitters [16]. With its potential as an ion conductor, the material needs to be modified and utilized as an alternative material such as ion delivery in the electrode membrane circuit in the DMFC Membrane and improving the mechanical properties of the membrane.

In this study, to make membrane composites modified anhydrous chitosan has been fabricated and it is expected to maintain membrane conductivity and reduce crossover methanol when the electrolyte membrane characteristics are tested as the basis of operation in DMFC.

\section{METHOD}

\section{A. Tools and Materials}

\section{1) Material.}

The materials used in this study were: Shrimp Skin Powder, 37\% Chloride Acid, Sodium dioxide, Dimethylformamide, Anhyditda Phthalate, Demineralization Aqua, and Sulfuric Acid.

2) Tool.

A set of grinding machines, magnetic stirrers, ovens, desiccators, analytical scales, stopwatches, FTIR spectrophotometers, statives and clamps, universal $\mathrm{pH}$, thermometers, centrifugation devices, funnels, 100 mesh sieves, and other glass equipment that are commonly used in laboratories.

\section{B. Chitosan Extraction}

The study was divided into 3 stages, namely chitosan extraction, matrix modification, and matrix analysis.

\section{1) Chitosan Preparation}

Shrimp (Penaeus kerathurus) waste, were washed thoroughly with tap water, dessicated at room temperature and milled (sieved from $2 \mathrm{~mm}$ to $5 \mathrm{~mm}$ ). After drying, were kept at room temperature until used [14].

\section{2) Deprotonation (Hong Method)}

Shrimp skin powder size of 100 mesh was dissolved in $3.5 \% \mathrm{NaOH}$ with a ratio of $10: 1(\mathrm{v} / \mathrm{b})$, shredded the dissolved shrimp and heated it in the extractor and stirred using a magnetic stirrer for 2 hours at $65^{\circ} \mathrm{C}$. After being cold, filtered and neutralized with distilled water. The solid obtained is dried in the oven without solvents at $105^{\circ} \mathrm{C}$ until dry.

\section{3) Demineralization (Hong Method)}

Demineralization was performed using hydrochloric acid $1 \mathrm{M}$ with a solid-to-solution ratio of 1:15 (wt/vol) at temperature $65^{\circ} \mathrm{c}$ for $30 \mathrm{~min}$. After the reaction time was complete, the mixture was filtered through coarse filter paper, then the filtrate was washed with deionized water to neutralize, and the solid obtained is dried in the oven without solvents at $105^{\circ} \mathrm{C}$ until dry. Finally, a 


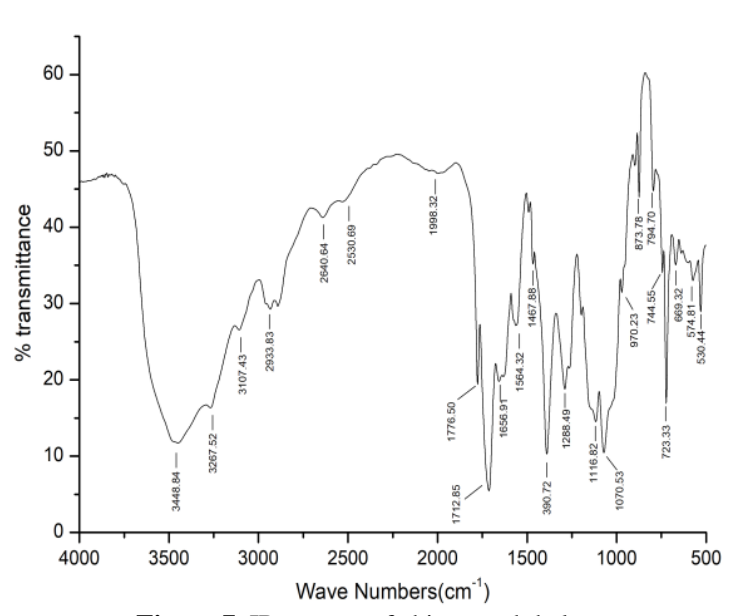

Figure 7. IR spectra of chitosan phthalate.

demineralization sample is obtained, which is called chitin. The solids obtained are identified both qualitatively and quantitatively whether they contain chitin. Qualitatively, we can detect the presence of Van Wesslink color reactions. In this way, chitin is reacted with $\mathrm{I} 2$ in $\mathrm{KI}$ which gives a brown color, then if added sulfuric acid changes to violet. The color change from brown to violet shows a positive reaction with chitin. Quantitatively to identify a chitin compound carried out by FTIR analysis (Agustina, 2015). The synthesized chitin was characterized by Fourier transformed infrared (FT-IR) spectroscopy (Bruker Alpha-T) in the range of 500 to $4000 \mathrm{~cm}^{-1}$.

The crystallinity of chitosan in powder form was studied by X-ray diffraction method (Bruker D8) using $\mathrm{Cu} \mathrm{K \alpha}$ radiation generated at $40 \mathrm{kV}$ and $40 \mathrm{~mA}$ at scanning speed of $0.32 \theta / \mathrm{min}$ within a range of $5^{0}$ to $35^{\circ}$.

\section{4) Deacetylation}

Chitosan synthesis through the deacetylation process using Knorr's method [5]. The results obtained from the deproteination process (chitin) were followed by a deacetylation process by adding $50 \% \mathrm{NaOH}$ with a ratio of 1:10 (b/v). The mixture was stirred and heated at 120 $\mathrm{oC}$ for 4 hours with a stirring speed of $50 \mathrm{rpm}$. The solids are washed with distilled water several times until the $\mathrm{pH}$ is neutral. The solid is then dried in an oven at $80 \mathrm{oC}$ for 12 hours then cooled in a desiccator and weighed until the weight is constant. Chitosan obtained was then characterized both qualitatively and quantitatively. Qualitatively to test the presence of chitosan using ninhidrine solution while quantitatively the chitosan obtained was characterized using FTIR and XRD. To find out the degree of deacetylation (DD) the base line method is proposed by Domszy and Rovert [5].

The synthesized chitin was characterized by Fourier transformed infrared (FT-IR) spectroscopy (Bruker Alpha-T) in the range of 500 to $4000 \mathrm{~cm}^{-1}$.

The crystallinity of chitosan in powder form was studied by X-ray diffraction method (Bruker D8) using $\mathrm{Cu} \mathrm{K \alpha}$ radiation generated at $40 \mathrm{kV}$ and $40 \mathrm{~mA}$ at scanning speed of $0.32 \theta / \mathrm{min}$ within a range of $5^{0}$ to $35^{\circ}$.

\section{Matrix Modification}

1) Chitosan modification with Anhydrous Phthalate

27.7 grams of chitosan was reacted with 64.5 grams of anhydrous phthalate in a solution of N, Ndimethylformamide 100 million under oxygen flow for 5 hours at $130{ }^{\circ} \mathrm{C}$. After that, it is precipitated with cold water and the solids obtained are washed with ethanol and diethyl ether to obtain yellow solids. Chitosan modified powder was analyzed by FTIR and XRD.

2) Chitosan and Chitosan Phthalate Matrix Analysis

The sample is prepared as much as 0.15 grams and mixed with a number of $\mathrm{KBr}$ then crushed to homogeneous. Then it was made in the form of pellets and characterized using FTIR at wave numbers $500-4000 \mathrm{~cm}^{-}$ 1

Determination of Degrees of Deacetylation (DD) based on FTIR Spectrum (Domszy and Robers Method). Quantitative methods using infrared spectrophotometry can be done by calculating $\%$ transmittance or absorbance. Calculation of deacetylation degree (DD\%) from infrared spectra on chitin and chitosan can be done by comparing absorbance at wave number for $\mathrm{NH}$-amide groups (1650$1500) \mathrm{cm}^{-1}$ (A 1655) with absorbance at wave number for primary amine group (3500-3200) $\mathrm{cm}^{-1}$ (A 3450), with an absorbance value of 1.33 in the perfect deacetylation process.

The equation used is as follows:

$$
\% D D=100-\left[\left(\frac{A 1655}{A 3450}\right) \times \frac{100}{1,33}\right]
$$

Where:

A1665 = Absorbance at wave number $1665 \mathrm{~cm}^{-1}$ A3450 = Absorbance at wave number $3450 \mathrm{~cm}^{-1}$

1.33 = constant obtained from the ratio A1665 / A3450 for chitosan with full acetylation

3) Identification of Chitin and Chitosan Compounds Chemically

The chemical identification of chitin and chitosan compounds includes analysis of chemical instrumentation by using the Fourier Transform Infra-Red (FTIR) spectrophotometer.

\section{RESULTS AND DISCUSSION}

\section{A. Chitosan Extract}

The extraction of chitosan from shrimp shells was carried out through four stages, namely the preparation, deproteinization, demineralization and deacetylation stages. The preparation stage starts from drying the shrimp skin in the sun and refining it using a blender to obtain the shrimp powder that passes the 100 mesh sieve.

The protein content of shrimp prawns is quite large, which is around $25-44 \%$ of the dry matter. These protein elements bind chitin physically and covalently. Therefore, to produce chitin, the process of breaking the bonds with chitin is called the deproteinsation process. In the proteination process, it is done by recording $\mathrm{NaOH}$ in extraction, so that the protein will dissolve in $\mathrm{NaOH}$. In a deproteinization reaction occurs, a little bubble is formed on the surface of the solution and the solution in the extractor becomes slightly thick and reddish in color. Thickening of the solution in the extractor is due to the protein content in crude chitin which is released and binds to the $\mathrm{Na}+$ ion in solution, forming sodium proteinate. The yield after deproteination is $30 \%$. This indicates that the protein content in the shell of the shrimp has already been released and that with $\mathrm{NaOH}$ forming an amino acid the reaction equation is shown in Figure 1. The deproteination stage uses $3.5 \% \mathrm{NaOH}$ with the aim of separating protein bonds from chitin [17]. 


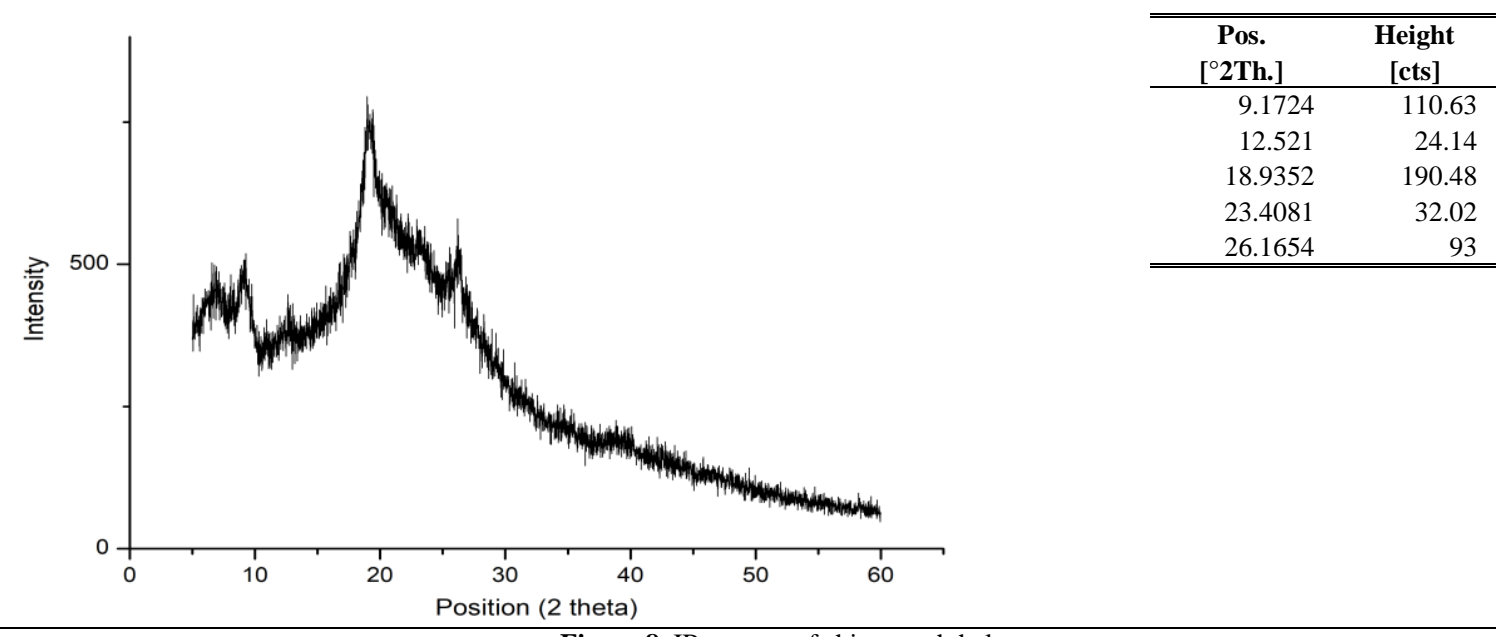

Figure 8. IR spectra of chitosan phthalate.

The next stage is the Demineralization stage. It aims to remove minerals from the shrimp shell. The main minerals in shrimp shells are Calcium carbonate $\left(\mathrm{CaCO}_{3}\right)$ and Calcium phosphate $\mathrm{Ca}_{3}\left(\mathrm{PO}_{4}\right)_{2}$. These minerals can be removed by revealing $\mathrm{HCl}$ solution. In the demineralization process, which is mixing shrimp shell waste with $1 \mathrm{~N} \mathrm{HCl}$ solution in the extractor, a significant reaction occurred. Subsequently, many bubbles and air bubbles are formed with a large enough volume, and this lasts for approximately 5-10 minutes. This is caused by the formation of $\mathrm{CO}_{2}$ and $\mathrm{H}_{2} \mathrm{O}$ gases on the surface of the solution based on the demineralization reaction shown by equations (1) and (2).

$$
\begin{gathered}
\mathrm{CaCO}_{3}(s)+2 \mathrm{HCl}(a q) \rightarrow \mathrm{CaCl}_{2}(a q)+\mathrm{CO}_{2}(g)+ \\
\mathrm{H}_{2} \mathrm{O}(l) \\
{\left[\mathrm{Ca}_{3}\left(\mathrm{PO}_{4}\right)_{2}\right](s)+6 \mathrm{HCl}(a q) \rightarrow 3 \mathrm{CaCl}_{2}(a q)+} \\
2 \mathrm{H}_{3} \mathrm{PO}_{4}(l)
\end{gathered}
$$

Deacetylation is the process of changing an acetyl group (-NHCOCH3) to chitin into an amine group (-NH2) with the addition of strong bases such as $\mathrm{NaOH}$. The deacetylation reaction of chitin is basically an amide hydrolysis reaction of $\alpha$ - (1-4) -2-acetamide-2-deoxy-Dglucose. The $\mathrm{OH}$-ion concentration is very influential on the process of releasing the acetyl group from the chitin acetamide group. According to Azhar, states that the stronger a base the greater the $\mathrm{OH}$-concentration in the solution that can increase base strength affects the deacetylation process of the acetyl group from the chitin acetamide group see Figure 2 [18].

\section{B. Characterization of Chitin and Chitosan with FTIR and $X R D$ Spectrophotometers}

Characterization of chitin and chitosan from fanami shrimp shells was carried out using FTIR spectrophotometry. The following are presented IR spectra of chitin and chitosan from fanami shrimp shells. In IR chitosan spectra from fanami shells in Figure 3, absorption bands appeared at wave numbers $3433.41 \mathrm{~cm}$ 1 which showed the presence of stretching vibrations in the $-\mathrm{OH}$ group and overlapping $\mathrm{N}-\mathrm{H}$ groups, stretching vibration of the $\mathrm{N}-\mathrm{H}$ amide group in chitin (figure 4) appears at wave number $3446.91 \mathrm{~cm}-1$, this absorption band does not appear at all in the spectra of fanami shrimp shell chitosan. This reinforces that the acetyl group release has occurred. The absorption band at a wavelength of $2885.60 \mathrm{~cm}^{-1}$ indicates a stretching vibration of the aliphatic $\mathrm{C}-\mathrm{H}$ group. The appearance of the absorption band at wave number $1653.05 \mathrm{~cm}^{-1}$ indicates a stretching vibration of the functional group $\mathrm{C}=\mathrm{O}$ carbonyl that is still present in chitosan. At wave number $1587.47 \mathrm{~cm}^{-1}$ the absorption band appeared on chitosan which identified the $\mathrm{N}-\mathrm{H}$ group (bending vibration), this band did not appear in chitin spectra. The vibration bending of the $\mathrm{C}-\mathrm{H}$ group is shown by the peak at wave number $1421.58 \mathrm{~cm}^{-}$ 1 , Vibration the methyl group found in chitin and chitosan was shown at wave number $1383.01 \mathrm{~cm}^{-1}$ characterization using FTIR spectrophotometer are shown in Figure 3 and 4.

The results of analysis by FTIR spectrophotometer shown in Figure 4 show that there is absorption of chitosan functional groups including absorption at wavenumber $3504.42 \mathrm{~cm}^{-1}$ which shows stretching vibration of $\mathrm{OH}$ groups, absorption with low intensity in the area of $2923.88 \mathrm{~cm}^{-1}$ shows symmetrical vibration $\mathrm{CH}_{3}$, in area $1635.52 \mathrm{~cm}^{-1}$ and $1542.95 \mathrm{~cm}^{-1}$ which shows stretching vibrations of $\mathrm{C}=\mathrm{O}$ groups and bending vibrations of NH groups [19].

The absorption of functional groups of chitosan has shown the character of chitosan functional group with a fairly good deacetylation degree value. Based on the calculation, the DD price using the baseline method is $84.55 \%$ which indicates that the chitosan used is good enough (DD chitosan standard is $>60 \%$ ).

Chitosan as one of the precursors in the composite was characterized by functional groups and determined the price of the degree of deacetylation (DD) which is one of the important parameters for the application of chitosan. The results of chitosan functional group stretching of the $\mathrm{C}-\mathrm{N}$ chitosan group appears on the absorption band $1249.91 \mathrm{~cm}-1$ and the $\mathrm{C}-\mathrm{O}$ stretching group is identified at wave number $1033.88 \mathrm{~cm}^{-1}$.

Based on the results of X-ray diffraction analysis as shown in Figure 5 and 6 it is known that there is a decrease in chitosan crystallinity which in chitin the diffraction peak pattern at position $2 \theta$ around 90 is at $714.74 \mathrm{cts}$ and $19^{\circ}$ at 677.07 cts while for chitosan the peak diffraction pattern is at position $2 \theta$ around $9^{0}$ decreased which was at 609.88 cts and 19 o at 550.03 cts. The high crystallinity of chitin is due to the hydrogen bond that occurs between the hydroxyl groups and the intramolecular and intermolecular $\mathrm{N}$-acetyl groups, intramolecular $-\mathrm{OH}$ in C3 to the oxygen rings which intersect with $\beta$ - (1-4) bonds. The hydrogen bond causes chitin to have a rigid structure, resulting in chitin having a low solubility in 
acid. Chitosan is insoluble in water and some organic solvents. The non-dissolution of chitosan in water and organic solvents is due to its crystal structure tends to be amorphous. So the results obtained that the crystallinity of chitosan is not too high or tends to be amorphous, indicating that the chitosan is good enough because it does not show chitin crystalline character, which is also supported by data calculation of chitosan deacetylation using FTIR spectrophotometer which reached $84.55 \%$.

\section{Characterization of Chitosan Phthalates with FTIR and XRD Spectrophotometers}

The FTIR test results of chitosan phthalate can be seen in Figure 7. The characterization of chitosan phthalate using FTIR, the peak that appears in the IR chitosan phthalate spectrum is in 1656.91-1564.32 cm-1 which shows the presence of amide groups and aromatic peak groups in the area of $1631.83 \mathrm{cn}-1$ which shows the addition of clusters not found in chitosan, where the IR spectrum of chitosan does not peak in the area which can be seen in Figure 4. This is because chitosan does not have an aromatic group in its structure.

The XRD test results of chitosan phthalate in figure 8 , the diffraction peak pattern at position $2 \theta$ around $9^{\circ}$ are at 110.63 cts and $18^{\circ}$ are at 190.84 . This can be compared with chitosan which decreases the crystallization because it is affected by the aromatic group on chitosan phthalates. The addition of anhydridaftate to chitosan can affect the level of solubility in water and organic solvents because the crystalline structure tends to be amorphous. The results obtained that the crystallinity of chitosan phthalate is not too high or tends to be amorphous so it cannot absorb too much water when applied to DMFC membranes.

\section{CONCLUSION}

This research has succeeded in extracting chitin and chitosan compounds from shrimp skin through deproteinization reaction with $\mathrm{NaOH}$, demineralization with $\mathrm{HCl}$, and deacetylation with $\mathrm{NaOH}$ and then modified chitosan with ftalet anhydride to produced chitosan Phthalate. Shrimp skin is $50.88 \%$ for chitin and $84.25 \%$ for chitosan. The results of characterization with FTIR and XRD showed that the extracted compounds were chitin and chitosan. The results of characterization with FTIR and XRD on chitosan phthalate showed that it could reduce near-absorption crystallization so that it could reduce water absorption and withstander high temperatures.

\section{AKNOWLEDGEMENTS}

The first author is thankful to Tribuan Alor foundation for their post-graduate scholarship. We thank to the head of the Materials and Energy Chemistry laboratory, for assistance in facilitating our research.

\section{REFERENCES}

[1] F. Adam, K. H. Dery, and S. W. Mada, "Perancangan Alat Pendeteksi Kadar polusi Udara Mengunakan Sensor Gas MQ7 dengan Teknologi Wireless HC-05," J. Istek, vol. X, no. 2, 2017.

[2] Q. Li et al., "High-Performance Direct Methanol Fuel Cells with Precious-Metal-Free Cathode," Adv. Sci., vol. 3, no. 11, 2016.

[3] M. Goor, S. Menkin, and E. Peled, "High power direct methanol fuel cell for mobility and portable applications," Int. J. Hydrogen Energy, 2018.

[4] K. Peng, J. Lai, and Y.-L. Liu, "Nanohybrids of graphene oxide chemically-bonded with Nafion: Preparation and application for proton exchange membrane fuel cells," $J$. Memb. Sci., vol. 514, pp. 86-94, 2016.

[5] B. Smitha, S. Sridhar, and A. Khan, "Chitosan-poly(vinyl pyrrolidone) blends as membranes for direct methanol fuel cell applications," J. Power Sources, vol. 159, no. 2, 2005.

[6] B. Ong, S. Kamarudin, M. Masdar, and U. Hasran, "Applications of graphene nano-sheets as anode diffusion layers in passive direct methanol fuel cells (DMFC)," Int. J. Hydrogen Energy, vol. 42, no. 14, pp. 9252-9261, 2016.

[7] B. P. Chang, H. M. Akil, and R. M. Nasir., "Mechanical and Tribological Properties of Zeolite-reinforced UHMWPE Composite for Implant Application," Procedia Eng., vol. 68, pp. $88-94,2013$.

[8] B. Tripathi and V. K. Shahi, "Organic-Inorganic Nanocomposite Polymer Electrolyte Membranes for Fuel Cell Applications," Prog. Polym. Sci., vol. 36, pp. 945-979, 2011.

[9] C. Nugraeni, "Montmorilonit Termodifikasi Aptes sebagai Filler dalam Membrane DMFC Berbasis Kitosan Termodifikasi Anhidrat Ftalat," Intitut Teknologi Sepuluh Nopember, 2018.

[10] Wan and et al, "Synthesis, Characterization and Ionic Conductive Properties of Phosphorylated Chitosan Membranes," Macromol Chem. Physic, vol. 204, pp. $850-$ $858,2003$.

[11] S. Sonawane, Y. Setty, and S. Sapavatu, Chemical and bioprocess engineering: Trends and developments. CRC Press, 2015.

[12] D. Gómez-Ríos, R. Barrera-Zapata, and R. Ríos-Estepa, "Comparison of process technologies for chitosan production from shrimp shell waste: A techno-economic approach using Aspen Plus ${ }^{\circledR}$ Food Bioprod,” Process, vol. 103, pp. 49-57, 2017.

[13] M. Nouri, F. Khodaiyan, S. Razavi, and M. Mousavi, "Improvement of chitosan production from Persian Gulf shrimp waste by response surface methodology Food Hydrocoll." 2016.

[14] S. Hajji et al., "Structural differences between chitin and chitosan extracted from three different marine sources," Int. J. Biol. Macromol., vol. 65, pp. 298-306, 2014.

[15] P. Mukoma, B. Jooste, and H. Vosloo, "A comparison of methanol permeability in Chitosan and Nafion 117 membranes at high to medium methanol concentrations," J. Memb. Sci. vol. 243, pp. 293-299, 2004.

[16] L. O. A. N. Ramadhan, C. L. Radiman, V. Suendo, D. Wahyuningrum, and S. Valiyaveettil, "Synthesis and characterization of Polyelectrolyte Complex NSuccinylchitosan-chitosan for Proton Exchange Membrane," Procedia Chem., pp. 114-122, 2012.

[17] F. Ahing and N. Wid, "Extraction and Characterization of Chitosan from Shrimp Shell Waste in Sabah," Trans. Sci. Technol., vol. 3, pp. 227-237, 2016.

[18] I. Tsigos, A. Martinou, D. Kafetzopoulos, and V. Bouriotis, "Chitin deacetylases: new, versatile tools in biotechnology," Trends Biotechnol., vol. 18, no. 7, pp. 305-312, 2000.

[19] S. Tan, E. Khor, T. Tan, and S. Wong, "The degree of deacetylation of chitosan: advocating the first derivative UVspectrophotometry method of determination," Talanta, vol. 45, pp. 713-719, 2005. 